\title{
OBSERVACIONES METODOLOGICAS PARA ESTUDIAR EL IMPACTO DE LA REVOLUCION FRANCESA EN LAS CLASES SUBALTERNAS*
}

\author{
Mario Aguilera Peña** \\ Renán Vega $C$.
}

A continuación se efectúan algunas observaciones de tipo teórico y metodológico para estudiar el impacto de la Revolución Francesa sobre las clases subalternas. De una manera sucinta se consideran tres aspectos: en primer lugar se muestran los mecanismos específicos que permiten a las clases subalternas recepcionar las influencias ideológicas, políticas y culturales de la Revolución. Entre tales mecanismos sobresalen la simbología, el sincretismo mental, la resemantización lingüís tica y la apropiación mítica de un legado o de un discurso revolucionario. En segundo lugar, se señalan los elementos derivados de la Revolución Francesa que más incidieron en la ideología de la protesta popular, porque le proporcionaron un sentido a la acción de los sectores subalternos (como sucedió con las nociones de derechos humanos y de soberanía popular). En tercer lugar, se analiza el as unto de la democracia, que corno problema político práctico surgió a partir de la Revolución Francesa, con un discurso igualitario que fue asimilado por las clases subaltemas y convertido en soporte de sus luchas cotidianas (expresado en foma clara en el lema "libertad, igualdad y fraternidad").

\subsection{LA APROPIACION SIMBOLICA DE LA REVOLUCION FRANCESA POR PARTE DE LOS SECTORES POPULARES}

En el estudio del influjo de la Revolución Francesa sobre el continente americano y sobre Colombia en particular, ha predominado el análisis de sus repercusiones en la época de la independencia y su influencia ideológica entre la élite que dirigió la emancipación. En este sentido, a la Revolución Francesa se le ha visto como una de las CAUSAS EXTERNAS de la independencia. Por lo mismo, los anális is se han centrado en estudiar los antecedentes de la influencia ideológica de ese suceso, los cuales quedan reducidos al estudio de la ilustración, del iluminismo y de los progresos (le las ciencias y de las artes, auspiciados por los filósofos y pensadores franceses durante el siglo XVIII. El estudio de este influjo se examina abordando los escritos de los llamados PRECURSORES que, como en el caso de

\footnotetext{
"Primera parte del trabajo titulado "Revolución Francesa: Simbología y movimiento popular", con el cual los autores obtuvieron el premio del Concurso Impacto de la Revolución Francesa en la sociedad colombiana. Este concurso fue organizado Conjuntamente por la Universidad Nacional y el Fondo de Promoción Cultural del Banco Popular. La obra mencionada será publicada próximamente.

${ }_{* * *}^{*}$ Profesor de Historia U.P.T.C.

${ }^{* * *}$ Profesor de Historia Universidad Pedagógica Nacional
} 
Antonio Nariño en la Nueva Granada, se encargaron de introducir "subrepticiamente" la ideología revolucionaria francesa.

Con esa perspectiva queda la impresión de que la ideología irradiada por la revolución de 1789 sólo afecto a las ELITES criollas de cada colonia y que pasó desapercibida para el resto de la población. Según esa visión, la Revolución Francesa no solo llegó a nuestros países por acción de las ¿lites letradas y "cultas", sino que además únicamente ellas tuvieron el privilegio de apropiarse de la herencia ideológica y de la cultura política legada al mundo por ese gran acontecimiento.

Esta concepción elitista desconoce las formas particulares de acción de la cultura y mentalidad populares ante un acontecimiento tan importante como el aquí considerado. En realidad no es cierto que los sectores populares -las cas tas a fines de la época colonial y sus herederos de la postindependencia hayan sido unos receptores pasivos de los mensajes difundidos por las élites dominantes. Por el contrario, contaban con una cultura propia que les permitió asimilar a su manera e interés tanto el discurso ideo-político, como las expectativas que el proceso generaba.

Por fortuna hoy en día, ante el avance en el estudio de las culturas populares por parte de diversas disciplinas de las ciencias sociales (como la Antropología, la Etnología, la Sociología, la Comunicación, etc.). es posible contar con instrumentos analíticos útiles para la historia de la cultura popular. Tanto las disciplinas señaladas como los pocos estudios históricos adelantados sobre el tema de las CULTURAS POP ULARES, han precisado elementos teóricos que es necesario retomar aquí, pues los mismos son claves para entender nuestra particular interpretación sobre la forma como los sectores populares recepcionaron los ideales de la Revolución Francesa.

Ya a comienzos del siglo XX, distintos autores des de el campo de la psicología de la mentalidad (o de masas) intentaron abordar el efecto de los procesos revolucionarios sobre los sectores populares. Gustavo Le Bon escribió a propósito un estudio titulado "La Revolución Francesa y la psicología de las revoluciones", que era una continuación de sus diferentes escritos sobre la psicología de la multitud y una aplicación de sus principales tesis al caso de la Revolución Francesa ${ }^{1}$.

Para Le Bon el efecto de una Revolución sobre la mentalidad popular era destructivo, pues en períodos de turbulencia social se despertarían las nociones más indeseables y brutales de la multitud. Eso posibilitaría que la multitud fuera fácilmente arrastrada por los demagogos de cualquier clase que, según Le Bon, siempre se constituirían en sus jefes "naturales". Para Le Bon, entonces, la multitud simplemente es una masa informe que en períodos de desestabilización social y política saca a relucir sus escondidos instintos brutales, pero que no

${ }^{1}$ Le Bon, Gustavo. La Revolución Francesa y la psicología de las revoluciones. Librería Gutcmbcerg de José Ruíz, Madrid, 1914. 
actúa, bajo ninguna circunstancia, ni en forma racional ni ordenada. La multitud es un simple agregado de personas que en momentos críticos se torna inmanejable y que puede ser arras trada a la destrucción por parte de sus líderes, quienes a su vez, según el autor francés, históricamente siempre han sido personas resentidas y frustradas que emplean ese resentimiento al servicio del caos y la anarquía ${ }^{2}$.

Esta visión elitista no impidió, sin embargo, que Le Bon comprendiera que uno de los aspectos más importantes del influjo de una revolución en el "alma popular" se manifiesta a través de SIMBOLOS, que constituyen un elemento mucho más movilizador que un corpus teórico o ideológico bien es tructurado. A esa estructura mental cargada de símbolos Le Bon la denomina MENTALIDAD MISTICA. Esta a menudo explica los fenómenos sociales y humanos como regidos por fuerzas sobrenaturales, que se manifiestan en fórmula o hechos simbólicos de gran significación para esos sectores populares. En el caso de los sectores que tratamos, la mentalidad mística cobra todavía más resonancia, pues ella remite a una supuesta vuelta al ESTADO NATURAL IGUALITARIO, que debió existir antes de las desigualdades e injusticias de su presente. Como quien dice la mentalidad mística profesa un igualitarismo espontáneo.

En el caso de la Revolución Francesa ese igualitarismo se vio reforzado porque se convirtió en uno de sus símbolos centrales. Le Bon consideró que la igualdad fue el principio de la Revolución que más impactó a los sectores populares ${ }^{3}$. De su análisis general de la Revolución Francesa y su influjo sobre la mentalidad colectiva, Le Bon concluyó:

"Aunque la divisa republicana haya sido muy poco aplicada, tuvo una influencia muy grande. De la Revolución no han quedado más en el alma popular que las tres célebres palabras que resumen su evangelio y que sus armas propagaron a través de Europa"*.

Conclusión que es necesaria retomar, ya que a nuestro modo de ver recoge lo esencial del impacto mundial de la Revolución Francesa sobre las clases subaltemas. En efecto, por primera vez un proceso político adquirió tal dimensión que puso a la orden del día y con una fórmula simple (libertad, igualdad, fraternidad) los sueños milenarios y utópicos de casi todos los pueblos de la tierra. En adelante por doquiera esa mágica fómula sirvió como consigna -por décadasen las luchas adelantadas por esclavos, artesanos, campesinos y obreros de la mayor parte del mundo, tanto del industrial como del pre-industrial.

En la actualidad los distintos estudios que se realizan sobre la cultura tienden a entenderla como una PRODUCCION SIMBOLICA del hombre, que as ume una dimensión social. Así que la cultura no se reduce a la existencia de "bienes

\footnotetext{
${ }^{2}$ Una crítica moderna a la Concepción de Le Bon se encuentra en George Rude, La Multitud en La Historia, Siglo XXI Editores, Madrid, 1979, p.p. 18 y 204 y S.S.

${ }^{3}$ G. Le Bon, op. cit. p. 157.

${ }^{4}$ Ibid., p. 159.
} 
culturales" o productos artísticos, sino que involucra el lenguaje y los sistemas valorativos y perceptivos. Todo ello genera una cosmovisión con sus redes organizativas para la circulación de mensajes, lo que conduce a una particular ubicación espacial y manejo de la temporalidad por parte de los diferentes sectores sociales 5 .

Las culturas populares reaccionaron, por consiguiente, de una manera propia ante los símbolos difundidos por la Revolución Francesa, pues los percibieron, valoraron y asimilaron en concordancia con sus propios intereses y necesidades; desde luego diferentes de los sectores hegemónicos y dominantes. Esto explica las muy variadas y disímiles interpretaciones de la Revolución Francesa, contemporáneamente a la misma, durante todo el siglo XIX y primeras décadas del XX.

Las culturas populares tienen la posibilidad de "reelaborar simbólicamente", según la expresión de García Canclini ${ }^{6}$ y de reproducir un discurso determinado, porque se mueven paralelamente en dos espacios: dentro del mareo de la cultura hegemónica, y dentro de sus propias prácticas y formas de pensamiento. Mediante la "reelaboración simbólica" los sectores populares crean, conciben y manifiestan su realidad, así ésta sea subordinada en todos lo órdenes de la producción, la circulación y el consumo ${ }^{7}$. Lo importante es que los dos espacios están igualmente separados como unidos, de manera que hasta el habla de los diferentes sectores sociales es en parte una construcción propia, y también una RESEMANTIZACION del lenguaje. Dicha res emantización cons tituye una elaboración singular a partir de sus condiciones de vida y expresa una interacción conflictiva con los sectores dominantes.

En Colombia la apropiación simbólica y la reelaboración semántica de los ideales y consignas de la Revolución Francesa por parte de las clases subalternas fue una constante desde el mismo momento de la Independencia. Encontramos que en distintos momentos las consignas de libertad, igualdad, fraternidad, derechos humanos, democracia; o menciones a personajes como Danton, Marat, Robespierre; o a símbolos como la Marsellesa y las banderas rojas, fueron retomados por distintos sectores populares, entre los cuales sobresalieron los artesanos, el naciente movimiento obrero y hasta por el caudilo popular Jorge Eliécer Gaitán. Entre estos distintos sectores hay continuidad en la apropiación de los ideales de la Revolución Francesa, pero esa apropiación es bien distinta a la realizada por las élites y sectores "cultos" y letrados. Las nominaciones y

${ }^{5}$ Ortega Milton Eduardo. Cultura Popular y Comunicación. Cuadernos de Chasqui No. 12. Revista Latinoamericana dc Comunicación, Quito, 1986, p. 20.

${ }^{6}$ García Candini, Néstor. Las Culturas Populares en el Capitalismo, Premio Casa de las Américas. La Habana. 1982, p. 48

${ }^{7}$ Ibid., pág. 49. 
apelativos en sentido formal se mantienen, pero su significado para las clases subaltemas es divergente e impreciso, si se quiere. (ver Tabla No. 1)

Un ejemplo de las elaboraciones semánticas se da con relación a la palabra "socialismo". Esta noción derivada del socialismo utópico en un período posterior de la Revolución Francesa, se usa en Colombia desde mediados del siglo XIX. En la época, tanto en Francia como en Colombia, las clases subaltemas tendían a confundir el socialismo, con el igualitarismo implícito en la consigna central de los revolucionarios burgueses de 1789. Para distintos sectores, incluyendo a Gaitán y a los movimientos socialistas de los años veinte, la palabra socialismo era un complemento de los postulados democráticos de la Revolución Francesa, que no contradecía los planteamientos igualitarios de esa revolución.

En el caso señalado, la apropiación simbólica de la noción de socialismo era más importante que su precisión conceptual, ya que remitía al problema del igualitarismo y de la democracia; implicaba una crítica abierta o implícita de las condiciones sociales existentes tal como la veían, en cada momento histórico, los sectores más lúcidos de las clases subaltemas.

\subsection{EL IMPACTO DE LA REVOLUCION FRANCESA EN LA IDEOLOGIA DE LA PROTESTA POPULAR}

Un primer as pecto para abordar el problema del impacto de la Revolución de 1789 en el movimiento popular, conduce a establecer relaciones entre la mentalidad y la protesta de los sectores subalternos. En este sentido creemos que es, en momentos de fermentación y de revuelta, cuando sale a relucir el bagaje de actividades y composiciones retroalimentadas durante muchas décadas por los mitos e ideologías igualitarias de diverso origen, entre ellos los derivados de la Revolución Francesa. Así tenemos, que la subversión social es el momento privilegiado para percibir las ideas igualitarias de las castas de color a finales del siglo XV III, para entender las nociones republicanas de los artesanos de mediados del siglo XIX, o para percibir el peculiar socialismo de los obreros de los años veinte del presente siglo.

Desde luego que esto no es exclusivo del caso colombiano, puesto que en cada uno de los acontecimientos políticos de gran participación popular en la Francia del siglo XIX, el recuerdo de la gran revolución de 1789 fue permanente y su presencia simbólica se sostenía viva entre los agentes populares que actuaban en esos procesos. Tal cosa sucedió en 1830, en 1848 y hasta en la Comuna París en 1871. En los sucesivos acontecimientos de la Francia decimonónica en los cuales los ti bajadores desempeñaron un papel protagónico, reivindicación central de la acción popular no pretendió instaurar conscientemente un REGIME SOCIALISTA o algo parecido, sino simplemente hacer realidad la REPUBLICA DEMOCRATICA Y SOCIAL, pregonada por los revolucionarios de finales del siglo XVIII ${ }^{8}$. Para solo citar un caso, en 1848 el socialis ta utópico Louis Blanc planteaba que el programa

${ }^{8}$ Rude, G. Revuelta Popular y Conciencia de clase. Ed. Crítica, Barcelona, 1981, p.126. 
para una auténtica reforma social en Francia suponía constitución de un poder democrático que tuviera "la soberanía del pueblo por principio, el sufragio universal por origen, y por objetivo la realización de ésta fómula: Libertad, igualdad, fraternidad"?.

Un segundo elemento a considerar es que la Revolución Francesa aportó elementos novedosos las luchas populares durante todo el siglo XIX Introdujo dos conceptos claves que fueron agitados a lo largo y ancho del mundo, incluyendo América Latina: Los Derechos del Hombre y Soberanía Popular. El principal papel desempeñado por estas nociones consistió en que después de haber penetrado en la imaginación popular donde ya perdían su carácter abstracto y retórico "las revueltas y los disturbios tendieron a adquirir una nueva dimensión y asumir un contenido social e ideológico del que habían carecido anteriormente", ${ }^{10}$.

Esos principios de Soberanía Popular y de Derechos del Hombre se convirtieron en una guía espiritual e ideológica que fundamentaba las luchas emprendidas por las clases subalternas. Estas no solamente se alimentaban de sus propias experiencias del pasado y de sus sueños espontáneamente igualitarios, sino que contaban con todo horizonte cultural -de tipo simbólico- para iluminar sus luchas y fortalecer sus es peranzas.

Después de la Revolución Francesa y hasta el presente, la movilización popular se hace a nombre de la defensa de las grandes causas, tales como la igualdad, la soberanía popular, la libertad, etc. Con ella se desmoronan la lealtad popular hacia individuos, que tanto había predominado en el mundo medieval y precapitalista, incluyendo los movimientos milenaristas y mesiánicos. A cambio de las lealtades personales la insubordinación social empieza a defender los grandes principios u instituciones revolucionarias ${ }^{11}$.

Desde luego que ese trascendental cambio no fue repentino ni total, máxime en países como los nuestros con un acendrado sentimiento autocrático, caudillista y religioso. Como bien lo anota G. Rude, "solo gradualmente los blancos personales fueron reemplazados por principios o causas, y consecuentemente los antiguos métodos de la justicia 'natural' comenzaron a desaparecer"12.

Las ideas más representativas de la Revolución Francesa se convirtieron en el faro ideológico que iluminó la protesta popular, lo cual no quiere decir que las ideas, tradiciones, costumbres y mitos propios de las culturas populares dejaron de existir. Por el contrario, las ideas más iluminantes de la Revolución Francesa fortalecieron las tradiciones propias de las culturas inorgánicas de los sectores populares. Especial fuerza dentro de estas culturas adquiere el MITO -en el

\footnotetext{
9 Blanc, Louis. "La Reforma" en Bravo Pedro, Socialismo Premarxista. Universidad Central de Caracas. Caracas. 1961, p. 145.

${ }^{10}$ Rude, G. op. cit.., p. 241.

11 Ibid.., pp. 248-249.

12 Ibid..
} 
sentido que le atribuye Eduardo Galeano como "mito libertador" y no como "mito castrador"- ${ }^{13}$ que por lo general remite, sobre todo en épocas de crisis, al recuerdo de un mundo natural e igualitario, muy distinto a la desapacible realidad de su presente, que la crisis tiende a hacermás intolerable.

En el caso de los indios, los esclavos y aún los mestizos del Nuevo Reino de Granada, afectados por un sistema de opresión colonial, adquirió dimensión la idea mítica sobre la existencia de un pasado feliz al que había que retornar o reconstruir. Se prefiguraba un poco en este caso, aquello que Mariátegui consideró para el Perú de los años veinte de este siglo (cuando en medio de una gran ebullición social emergieron utopías andinas que se remitían hasta el milenario pasado incaico con el fin de justificar sus luchas contra los terratenientes y gamonales), al sostener que la "fuerza de los revolucionarios no está en su ciencia, esta en su fe, en su pasión, en su voluntad. Es una fuerza religiosa, mística, espiritual, es la fuerza del mito""14.

Un tercer elemento a tener en cuenta es que las motivaciones de la multitud no se reducen ni al influjo de ideas externas ("derivadas") como en el caso de las ideas generadas por la Revolución Francesa, ni tampoco al peso de las tradiciones, mitos y cosmovisiones propias ("ideas inherentes"). Además se involucran otra serie de factores, objetivos y subjetivos que muestran la complejidad de las razones que están detrás de cualquier movimiento de protes ta social. Como lo ha expresado G. Rude:

"La multitud puede levantarse porque está hambrienta o teme estarlo, porque busca una refoma inmediata o el milenario o porque quiere destruir a un enemigo o adamar un héroe. Pero rara vez lo hace solo por una de estas razones"

Las ideas importadas y las propias se mezclan en una forma particular de acuerdo con el contexto espacial y temporal para originar en cada caso una acción propia de la protesta popular y una percepción sincrética del momento histórico. La ideología de la protes ta popular "renueva" los enemigos en concordancia con la correlación de fuerzas de cada enfrentamiento. Para el caso de las luchas de los artesanos colombianos, por ejemplo, unas veces los enemigos fueron los comerciantes; en otras ocasiones los acaparadores y monopolistas, en otros momentos los panaderos (el "motín del pan" de Bogotá, en 1875), y en determinadas circunstancias hasta los "extranjeros" (el movimiento de La Culebra Pico de Oro en Bucaramanga en 1879).

Un cuarto elemento para entender el efecto de la Revolución Francesa en la ideología de la protesta popular, nos lo aporta el conjunto de creencias pre-

\footnotetext{
${ }^{13}$ Galeano, Eduardo. "El Arte Dc la Historia: Testimonio de una experiencia Literaria" en Revista de la Unión Nacional de Escritores, No.2, Bogotá, 1986, p. 20.

${ }^{14}$ Mariátegui, José Carlos. El Alma Matinal.. Ed. Amauta, Lima, 1976, p. 22.

${ }^{15}$ Rude, G. La Multitud p. 224.
} 
políticas de la multitud, que ha sido definid por G. Rude. Este historiador analiza como creencias ins tintivas las siguientes:

a. La antipatía hacia la innovación capitalista. Esta se manifiesta como un rechazo de $\mathrm{h}$ economía de pequeños productores, a las manifestaciones de los signos del capitalismo: los monopolios, la usura, las máquinas, etc.

\section{b. El gobierno como "padre" y protector}

Esta se concibe como una inclinación de las sociedades pre-industriales por considerar a las autoridades como figuras todopoderosas cuya función de supuestos orígenes divinos y celestiales consistiría en velar por el bien colectivo de sus súbditos.

c. El instinto nivelador. Se entiende como e deseo o anhelo de los pobres por obtener cierto grado de justicia social combatiendo a ricos poderosos, que son vistos como sus enemigos naturales ${ }^{16}$.

Las mencionadas creencias han sido planteadas en téminos de instintos espontáneos que se encuentran a nivel mundial entre los más diversos pueblos y culturas. Generalmente están relacionadas con sociedades precapitalistas en las que predomina un medio rural aparentemente estático y signado por la ideología religiosa.

La anterior indicación metodológica se refiere al ideario de las sociedades "arcaicas", que en su conjunto no se contrapone a los mismos valores creados en sociedades de transición al capitalismo industrial. Así, no podemos dejar de encontrar identidades entre el mito igualitario, el instinto nivelador y el sentimiento anticapitalis ta en las sociedades de Antiguo y Nuevo régimen. Esto nos previene para no caer en falsas escatologías respecto de la revolución francesa y de cualquier otra revolución. Las ideas "derivadas" (nuevas) recaen para mezclarse con las ideas “inherentes' (antiguas), pero nunca puede haber una sociedad, por más tradicional que sea, carente de ingenio y de fantasías liberadoras.

\subsection{LA REVOLUCION FRANCESA Y EL PROBLEMA DE LA DEMOCRACIA}

En las primeras fases de la Revolución Francesa, Babeuf, uno de los primeros comunistas prácticos, criticó mordazmente la pretendida igualdad originada en la Revolución Francesa. En "El manifiesto de los Iguales" se expresaba una forma diferente de interpretar la noción de igualdad, en comparación por ejem plo con los postulados de los filós ofos de la lustración. Concretamente Babeuf decía:

"No nos basta con que esta igualdad aparezca escrita en la declaración de los Derechos del Hombre y del ciudadano; la queremos entre nosotros bajo

\footnotetext{
${ }^{16}$ Para éste análisis general nos hemos basado en G. Ru de. La Multitud... pp. 234
} 
el techo de nuestras casas... Perezcan, si es preciso, todas las artes con tal que nos quede la igualdad real"17

Este planteamiento enfatizaba el problema de la democracia, no resuelto por la Revolución Francesa, pero colocado como exigencia práctica por primera vez en la historia de la humanidad. Para los liberales ese asunto era político-institucional y tenía que ver con la forma de organización político-administrativa que debía regir los destinos de una nación, pero no más. Para otros sectores, va des de el mismo momento de consumada la revolución, el asunto no debía remitirse exclusivamente al plano político - o sea con referencia al Estado y a las llamadas instituciones representativas - sino que era necesario considerar también el orden social y económico, en la medida en que se cuestionaban los logros formales (o reales pero para una sola clase) y se mencionaban los orígenes estructurales de la desigualdad; estos sectores eran defensores de una DEMOCRACIA SOCIAL, para los cuales "el derecho a la vida se antepone al derecho de propiedad"18.

Desde la revolución se perfilan las líneas que seguira la democracia en las décadas siguientes. Cobra fuerza la tendencia que ve a la democracia como una típica igualdad de derechos. Según esta concepción todos los ciudadanos son libres de ejercer sus derechos, pero poco importa cine estos tengan medios y oportunidades para ejercerlos. Con que solo estén expresados formalmente sobra y basta; que operen en la realidad para el conjunto de la población viene a ser un problema secundario. En esta perspectiva, se sobre valoró el derecho de PROPIEDAD, como se pudo comprobar en las disposiciones de la primera legislatura burguesa de la Revolución en Francia que los concibió como un "derecho natural", que no podía ser cuestionado de ninguna manera; esa legislación además mantuvo la esclavitud y restringió el derecho del sufragio solo a aquellos que pudieran pagar una determinada contribución económica. Desde el

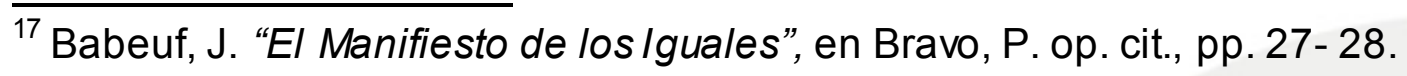

${ }^{18}$ Es interesante traer a colación el cinismo de que hacían gala algunos de los ideólogos más connotados de la burguesía revolucionaria francesa. Por ejemplo Voltaire consideraba como "inevitable que la humanidad esté dividida en dos clases con muchas subdivisiones; los obreros y los oprimidos. Afortunadamente (!!) la costumbre y la falta de ocio impiden a la mayoría de los oprimidos darse cuenta de su condición" (citado por Harold Lasky, El liberalismo Europeo, Ed. Fondo de Cultura Económica, México, 1939, p. 314). Y en su clásico libro sobre Luis XIV observó: "El jomalero y el artesano deben estar reducidos a los indispensable para hacerlos trabajar; esta es la naturaleza humana (!!). Es inevitable que la mayoría sea pobre; sólo es necesario que no sea miserable" (citado en H. Lasky, Op. Cit., p. 315). Otra mención significativa nos la proporciona un tal Rivarol que en agos to de 1789 -recién comenzada la revolución- decía: "Los negros de nuestras colonias y los criados de nuestra casa con la Declaración de los Derechos en la mano pueden expulsarnos de nuestras haciendas. Como una asamblea de legisladores finge ignorar que el derecho natural no puede existir junto con el de propiedad"? ? Citado por A. Soboult, "Utopia y Revolución Francesa" en J. Drotz, Op. Cit., p. 265. 
principio mismo de la Revolución Francesa los derechos reconocidos por la burguesía en su lucha contra el absolutismo del antiguo régimen, solo eran un privilegio burgués excluyente, porque para la gran masa de esa población siguieron siendo abstractos y retóricos. ${ }^{19}$

La brecha abierta por la Revolución Francesa en cuanto a la concepción burguesa y liberal de la democracia se ha mantenido hasta el presente. El asunto de la DEMOCRACIA constituye uno de los pilares del pensamiento político y social de los siglos XIX y XX y es una de las reivindicaciones permanentes de los distintos movimientos gestados desde entonces, tanto en Europa como en otros lugares del mundo, incluyendo a América Latina.

La cuestión de la democracia se torna más compleja en el siglo XIX porque las distintas corrientes del socialismo utópico van a reclamarla como uno de los objetivos políticos, enfatizando su deuda con la Revolución Francesa, en cuanto ese acontecimiento sirvió para hacer universal el reconocimiento -as í fuera formalde la soberanía popular, de la igualdad, y de la libertad política, etc.; pero reafimando que la pertinencia y actualidad de su socialismo radicaba en que solo a través de la organización "societaria" (en téminos de Fourier) era posible lograr la plena democracia social y económica y una verdadera libertad e igualdad. Leroux, al parecer el inventor de la palabra socialismo, criticaba mordazmente el concepto de igualdad liberal, cuando en un escrito de 1833 decía:

"Preguntad a los partidarios del individualismo lo que piensan de la igualdad de los hombres; por supuesto que se guardarán de negarla, pero para ellos solo es una quimera sin importancia, no tienen ningún medio de realizarla. Por el contrario, su sistema solo tiene por consecuencia la más infame desigualdad. Por lo tanto su libertad es una mentira, porque solo un número muy reducido goza de ella $y$ como consecuencia de esa desigualdad la sociedad se convierte en una guardia de bribones y de víctimas, un semillero de vicios, sufrimientos, inmoralidad y crímenes" 20

Esta era la continuación de lo que Rabeuf había denominado la sociedad escindida, para denotar cómo en Francia en plena revolución era bien distinta la concepción de REPUBLICA que manejaba un millón de privilegiados y los restantes 24 millones de franceses pobres ${ }^{21}$. Por esta circunstancia, la doctrina de Babeuf fue heredada por los socialistas de las más diversas tendencias. Lo más importante no era que se reivindicara su doctrina sino que se producía un vínculo

\footnotetext{
${ }^{19}$ lbid

20 Citado en Bravo, P. op. cit. p. 137

${ }^{21}$ Rarauf, G. "La sociedad Escindida" en Bravo, P. Op. Cit., p. 22. 
con la "verdadera historia del mundo popular durante la revolución con sus mitos y combates"22.

¿Por qué la Revolución Francesa se podía vincular en una forma tan relativamente simple con la utopía socialista? ¿Por qué precisamente fue en Francia donde, poco después de la revolución, la ideología socialista adquiere tan significativa importancia? Tal vezuna de las razones sea que la Revolución Francesa tenía su propia utopía, no únicamente porque existieran sueños visionarios sobre posibles reinos celestiales en la tierra -sueños que fueron muy frecuentes en Francia desde muchos años antes de la revolución ${ }^{23}$ sino, porque durante la revolución, emergió una corriente IGUALITARIA, arraigada en los sectores populares ya que estaba íntimamente vinculada a "las estructuras de una sociedad con predominio de artesanos y tenderos" ${ }^{24}$. Ese igualitarismo asumió en la Revolución Francesa dos tendencias: una arcaizante, que respondía a las exigencias populares de una sociedad agraria, precapitalista; y otra igualitarista utópica, pre-figuradora de los sistemas socialis tas del siglo XIX. En el curso mismo de la revolución predominó el primer tipo de igualitarismo, que miraba más hacia el pasado que hacía el futuro y que pretendía regresar a una supuesta sociedad natural, perfecta y as cética.

Pero también existió la utopía JACOBINA, tal vez de mayores repercusiones mundiales. Como lo ha remarcado A. Soboult, el jacobismo como pensamiento social estaba hecho a la medida de la "Francia rural, artesana y mercantil de la segunda mitad del siglo XVIII; una sociedad de pequeños productores independientes, cada uno de los cuales con su campo, su tienda, su instrumental, y capaz de alimentar a su familia sin recurrir al trabajo asalariado" ${ }^{25}$, Era paradójico que los jacobinos tuvieran ese pensamiento plebeyo y pequeño burgués, y lo intentaran llevar a la práctica, en un mundo en el que adquirían poder las impetuosas fuerzas del capitalismo. De ahí que los jacobinos pretendieran preservar la pequeña propiedad sin alterar el libre funcionamiento de las fuerzas económicas, fuerzas que destruían su economía de pequeños productores. Eso no era sino utopía.

Robespierre y sus amigos eran partidarios de una república de pequeños propietarios, pero pregonaban el Estado liberal en el sentido económico del término-; aborrecían la economía dingida desde el Estado, pese a que este pudiera ser el único soporte -hipotéticamente hablando- capacitado para garantizar el reino de las pequeñas fortunas. A los jacobinos les faltó una concepción histórica de las necesidades y posibilidades de su tiempo; para impulsar la revolución creían más en fuerzas espirituales y en la virtud, antes que en comprender las contradicciones de su época. Ya Marx y Engels en una de sus

\footnotetext{
${ }^{22}$ Matarich, Claude. Babeuf: Realismo y Utopía en la Revolución Francesa. Ediciones Península, Barcelona, 1970, p. 46.

${ }^{23}$ Soboult, A. Op. Cit., pp. 265

${ }^{24}$ Ibid.., p. 306 (el subrayado es nuestro).

25 Ibid., p. 300.
} 
primeras obras enfatizaban la terrible ambigüedad jacobiana al considerar como un

"error colosal el verse forzado (el jacobismo) a reconocer y sancionar con los derechos del hombre a la sociedad burguesa moderna, la sociedad de la industria, de la competencia general, de los intereses privados que persiguen libremente sus fines, de la anarquía, de la individualidad natural y espiritual convertidos en extraños a sí mismos, y querer anular luego en ciertos individuos las manifestaciones de esta sociedad, y al mismo tiempo modelar a la antigua la cabeza de esta sociedad" ${ }^{26}$.

Pese a todo, la utopía jacobiana había intentado llevar a la práctica, por primera vez en la historia con una dimensión mundial, el ideario de la DEMOCRACIA SOCIAL. Cosa que aterrorizó a burguesía francesa y a las clases dominantes $d$ mundo entero, hasta el punto que durante el siglo XIX el calificativo de "jacobino" era considera como un estigma, una ofensa que anticipaba fantasmales figuras apocalípticas del comunismo o del anarquismo. Para los sectores populares esa utopía jacobiana de democracia social alimentó las principales luchas emprendidas por el pueblo francés después de 1789, luchas que, nuevamente se movieron en el ámbito de la ambigüedad jacobina de querer preservar la pequeña propiedad e contra del impetuoso e incontenible avance del capitalismo con todas sus secuelas de expropiación, violencia, desempleo, concentración económica pauperización. De esta forma, el avance del capitalismo en lugar de atenuar la desigualdad la reforzaba y hacía que los sueños de libertad e igualdad de goces" de los jacobinos fueran imposibles. Pero así y todo:

"encadenados a su condición, los artesanos y tenderos, descendientes de los Sans-Culottes de 1793, siem pre ligados a la Pequeña propiedad basada en el trabajo personal, oscilaron entre la utopía y la rebelión. La misma contradicción entre la exigencia de igualdad de derecho prodamada como principio y las consecuencias del derecho de propiedad y de la libertad económica y la misma impotencia, pesaron sobre las tentativas de democracia social" 27

${ }^{26}$ Marx Carlos y Engels, Federico. La Sagrada Familia. Ed. Pluma, Bogotá, 1982.

${ }^{27}$ A. Soboult. Op. Cit. p. 305. 
TABLA No 1

\section{PROYECCIONES DE LA REVOLUCION FRANCESA EN LAS NOMINACIONES DEL MOVIMIENTO POPULAR COLOMBIANO}

\begin{tabular}{|c|c|c|c|c|}
\hline NOMINACION & AÑO & FRANCIA & AÑO & COLOMBIA \\
\hline $\begin{array}{l}\text { Guardia } \\
\text { Nacional }\end{array}$ & $1789-1781$ & $\begin{array}{l}\text { Surge en París el } 13 \text { de Julio, } \\
\text { bajo la dirección del Comité } \\
\text { "ilegal". } \\
\text { El nombre y la organización } \\
\text { militar son aprobados por la } \\
\text { Asamblea Nacional el } 5 \text { y } 10 \text { de } \\
\text { agosto. } \\
\text { La constitución de ese año } \\
\text { prevee que se reserven a } \\
\text { ciudadanos "activos" (1). }\end{array}$ & 1854 & $\begin{array}{l}\text { Creada por mandato de la } \\
\text { Constitución de 1832, como un } \\
\text { ejército de emergencia. No } \\
\text { vinculaba a "ciudadanos } \\
\text { activos", por ello estuvo conf or- } \\
\text { mada mayoritariamente por } \\
\text { artesanos. } \\
\text { Fue soporte básico en la dictadura } \\
\text { del general Jose'María Melo. Entre } \\
\text { sus oficiales figuraban los líderes } \\
\text { artesanales Miguel León, José M. } \\
\text { Vega y Cruz Ballesteros (10). }\end{array}$ \\
\hline $\begin{array}{l}\text { Conv ención } \\
\text { Nacional }\end{array}$ & $1792-1795$ & $\begin{array}{l}\text { La historia de la Conv ención se } \\
\text { divide en tres fases: } \\
\text { A. La Convención Girondina. } \\
\text { B. La Convención de la } \\
\quad \text { Montaña. } \\
\text { C.La Convención Termidoriana } \\
\text { (2). }\end{array}$ & 1854 & $\begin{array}{l}\text { Se busca legitimar la dictadura de } \\
\text { Melo por intermedio de la } \\
\text { conv ocatoria de una Convención } \\
\text { Nacional. Uno de los llamamientos } \\
\text { decía: "La Constitución, la } \\
\text { legitimidad son palabras, son } \\
\text { pretextos para (dominar) a los } \\
\text { pueblos. No hay otra tabla de } \\
\text { salvación que la Convención } \\
\text { Nacional" (11). }\end{array}$ \\
\hline $\begin{array}{l}\text { Comité de Salud } \\
\text { Pública }\end{array}$ & $1793-1794$ & $\begin{array}{l}\text { Fue un comité del gobierno } \\
\text { rev olucionario que sustituyó a la } \\
\text { Monarquía Feudal. Su labor era } \\
\text { complementada por el Comité } \\
\text { de Seguridad General. } \\
\text { El C. de Salud Pública vigilaba } \\
\text { la acción gubernamental: el } \\
\text { Consejo Ejecutivo, los generales } \\
\text { y los cuerpos constituidos. } \\
\text { Debía rendir informe semanal a } \\
\text { la Asamblea. } \\
\text { A escala Nacional se ocupa de } \\
\text { las subsistencia y de aplicar la } \\
\text { "política de Terror" (3). }\end{array}$ & 1889 & $\begin{array}{l}\text { Las sociedades de Salud Pública } \\
\text { fueron consideradas herederas de } \\
\text { las Sociedades Democráticas. Al } \\
\text { respecto se decía que cada vez } \\
\text { que el partido liberal subía al poder } \\
\text { "las formas de la Revolución } \\
\text { Francesa se reproducen en el acto } \\
\text { y v uelven los clubes políticos..." } \\
\text { Al parecer fueron organizaciones } \\
\text { clandestinas. Su nombre está } \\
\text { asociado a acciones terroristas } \\
\text { contra oponentes políticos: } \\
\text {-amenazaron y atacaron a los } \\
\text { senadores Ricardo Becerra y } \\
\text { Rafael Núñez (abril): } \\
\text {-Atacaron a bala al gobernador del } \\
\text { Estado de Cundinamarca, } \\
\text { General Daniel Aldana, que re } \\
\text { sulta herido. Su acompañante } \\
\text { perdió la vida (sep. 19) (12) }\end{array}$ \\
\hline $\begin{array}{l}\text { El amigo del } \\
\text { Pueblo }\end{array}$ & 1792 & $\begin{array}{l}\text { El dirigente revolucionario Juan } \\
\text { Pablo Marat (1743-1793) publica } \\
\text { un periódico con el nombre "El } \\
\text { Amigo del Pueblo". } \\
\text { Debido a sus vínculos con el } \\
\text { artesanado y el pueblo Ilano, } \\
\text { Marat recibió la denominación } \\
\text { de el Amigo del pueblo (4). }\end{array}$ & 1889 & $\begin{array}{l}\text { "El Amigo del Pueblo'. Periódico } \\
\text { de oposición fundado por } \\
\text { Alejandro Torres Amay a, Fue til- } \\
\text { dado de "anarquista" por la prensa } \\
\text { conservadora. Alcanzó } 12 \\
\text { ediciones hasta su suspensión } \\
\text { definitiva (13). }\end{array}$ \\
\hline
\end{tabular}




\begin{tabular}{|c|c|c|c|c|}
\hline Secciones & $1789-1794$ & $\begin{array}{l}\text { Estructuras organizativ as } \\
\text { urbanas, que se constituyen en } \\
\text { soporte de la revolución. } \\
\text { Teóricamente eran divisiones } \\
\text { electorales, pero se convirtieron } \\
\text { en el marco institucional de } \\
\text { asambleas de barrios (5). }\end{array}$ & 1894 & $\begin{array}{l}\text { Una organización clandestina que } \\
\text { pretendía darle un golpe de mano } \\
\text { al gobierno de Miguel A Caro: } \\
\text { divide los barrios de Bogotá } \\
\text { comprometidos en la conspiración } \\
\text { en secciones. Sus principales lí- } \\
\text { deres eran artesanos (14). }\end{array}$ \\
\hline La Humanidad & $1795-1840$ & $\begin{array}{l}\text { Periódico francés calificado de } \\
\text { Comunista, se considera que } \\
\text { continuó el pensamiento de } \\
\text { Babeuf, organizador de la } \\
\text { conspiración de los iguales. } \\
\text { Dirigido por Sy vain Maréchal, } \\
\text { un famoso orador Sans-culotte } \\
\text { (6). }\end{array}$ & $1925-1928$ & $\begin{array}{l}\text { Periodico Socialista dirigido por } \\
\text { Ignacio Torres Giraldo, uno de los } \\
\text { principales dirigentes del Partido } \\
\text { Socialista rev olucionario (P.S. R.) } \\
\text { (15). }\end{array}$ \\
\hline Germinal & $\begin{array}{l}1794 \\
1795\end{array}$ & 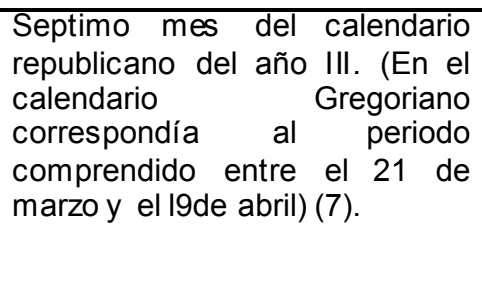 & $1926-1928$ & $\begin{array}{l}\text { Periódico socialista dirigido por } \\
\text { Ricardo E. López Editado en } \\
\text { Puerto Wilches. Vinculado a las } \\
\text { primeras luchas obreras en la zona } \\
\text { petrolera de. Barranca. Uno de sus } \\
\text { habituales colaboradores era Raul } \\
\text { E. Mahecha, dirigente del P.S.R. } \\
\text { (16). }\end{array}$ \\
\hline Jornada & $1789-1795$ & $\begin{array}{l}\text { El témino fue } \text { utilizado para } \\
\text { designar una manif estación } \\
\text { popular organizada y, y, } \\
\text { usualmente, amada (8). }\end{array}$ & 1945 & $\begin{array}{l}\text { Periódico fundado en } 1945 \text { por el } \\
\text { caudillo Jorge E. Gaitán. Conoció } \\
\text { tres fases diferentes: } \\
\text { A. Con motivo de la candidatura } \\
\text { presidencial de Gaitán } \\
\text { B. Reinagurado en } 1947 \\
\text { Existió hasta varios años después } \\
\text { del asesinato de Gaitán (17). }\end{array}$ \\
\hline $\begin{array}{l}\text { El tributo del } \\
\text { pueblo }\end{array}$ & $1795-1796$ & $\begin{array}{l}\text { Periódico fundado y dirigido por } \\
\text { Francois Noel Babeuf (1760- } \\
1797) \text {, considerado como padre } \\
\text { del primer 'movimiento } \\
\text { comunista práctico"(9). }\end{array}$ & $1944-1989$ & $\begin{array}{l}\text { Denominación con la que es } \\
\text { conocido Jorge E. Gaitán. Ese } \\
\text { apelativ o empezó a emplearse a } \\
\text { nales de la segunda } \\
\text { administración Lópe cuando es } \\
\text { postulada la candidatura de } \\
\text { Gaitán. Desde ese momento, } \\
\text { hasta el día de hoy, en periódicos, } \\
\text { discos y en la mentalidad popular } \\
\text { Gaitán es recordado como el } \\
\text { "Tribuno del Pueblo", tanto por sus } \\
\text { dotes oratorias como por su forma } \\
\text { hacer política, caracterizada por su } \\
\text { acercamiento a los sectores } \\
\text { populares (18). }\end{array}$ \\
\hline
\end{tabular}




\section{Fuentes}

(1), (2), (3), (8), Peronnet, Michel, Vocabulario de la Revolución Francesa, Editorial Crítica, Barcelona, 1985, pp. 36-38, 126; 73-78.

(4) Efimoy, A. et. al., Historia Moderna de 1642 a 1918, Editorial Grijalbo, Buenos Aires, 1975, pp. 79-80.

(5) Vovelle, Michel, Nueva historia de Francia Contemporánea. La caída de la Monarquía, 1787-92, Editorial Ariel, Barcelona, 1979, pp. 233-235.

(6) Drotz, J. Historia General del Socialismo, Editorial Destino, Barcelona, 1984, T.1.p. 533.

(7) Saboult, Albert, Los sans-Culotres. Movimiento Popular y Gobiemo revolucionario, Alianza Universidad, Madrid, 1987, pp. 243- 244.

(9) Droptz, J. Op. Cit. 1.

(10) Vargas Martínez, Gustavo, Melo, los artesanos y el socialismo, Editorial. Oveja Negra, Bogotá, 1972.

(11) El 17de Abril No. 3,21 de Mayo de 1854.

(12) E/conservador, Bogotá No. 157, 21 de septiembre de 1882; Diario de Cundinamarca, No. 3060,15 de abril 1882, Holguín, Carlos, Cartas Políticas, Editorial incunables, Bogotá, 1984, pp. 151-152.

(13) El Amigo del Pueblo, Bogotá, No. 1-12, Bogotá, agos to de 1989.

(14) Informe del Ministerio de Guerra, Julio 20 de 1984.

El Heraldo, No. 377, abril 30 de 1984, ISMAC, Centro de Documentación.

(15) Archila, Mauricio, "La Humanidad, el periódico obrero de los años veinte", En Boletín Cultural y Bibliográfico, vol XXII, No.3, 1985, pp ys.s.

(16) Memoria del Ministerio de Gobiemo al Congreso Anexos, tomo 2, Bogotá, Imprenta Nacional, 1929, pp. 26-27.

(17) Braun, J. Mataron a Gaitan , Ediciones Universidad Nacional de Colombia, Bogotá, p. 401. 
Alape Arturo, El Bogotazo, Editorial Pluma, Bogotá, 1984, pp. 61 y s.s.

(18) Córdoba, José Maria, Jorge Eliécer Gaitán: Tribuno Popular de Colombia, Bogotá, Litográficas Cor. Val, 1952. 